\title{
Factors associated with, and echocardiographic findings of heart failure among HIV infected patients at a tertiary health care facility in Dar es Salaam, Tanzania
}

\author{
MUHAMMAD BAKARI ${ }^{*}$, PILLY CHILLO ${ }^{2}$ and JOHNSON LWAKATARE ${ }^{1}$ \\ IMuhimbili University of Health and Allied Sciences, Department of Internal Medicine, P.O. Box 65001, Dar es \\ Salaam, Tanzania \\ ${ }^{2}$ Muhimbili National Hospital, Department of Internal Medicine, P.O. Box 65000, Dar es Salaam, Tanzania
}

\begin{abstract}
Cardiovascular diseases, including heart failure are a known complication of Human Immunodeficiency Virus (HIV) infection globally. The objective of this study was to describe factors associated with, and echocardiographic findings of heart failure among HIV infected patients at a tertiary health care facility in Dar es Salaam, Tanzania. Clinical, laboratory and echocardiographic assessment was performed in all HIV-infected patients presenting with cardiac complaints at the medical department, Muhimbili National Hospital between September 2009 and April 2010. HF was diagnosed clinically and confirmed by echocardiography. Of the 102 HIV-infected patients with cardiac complaints 50 (49\%) were in HF. Commonest causes of $\mathrm{HF}$ were hypertensive heart disease, pulmonary hypertension and dilated cardiomyopathy. In multivariate analysis male gender (OR 4.03), low education (OR 4.91), previous history of tuberculosis (OR 3.01), and low haemoglobin (OR 0.83), were independently associated with the diagnosis of $\mathrm{HF}$ ( $p<0.05$ for all). In conclusion, heart failure is common in HIV-infected patients with cardiac complaints, and is associated with both modifiable and non-modifiable factors.
\end{abstract}

\section{Keywords: HIV, heart failure, echocardiography, Tanzania}

\section{Introduction}

Cardiovascular diseases, including heart failure are a known complication of Human Immunodeficiency Virus (HIV) infection both in developing (Longo-Mbenza et al., 1998; Nzuobontane et al., 2002) and in developed countries (Butt et al., 2011; Herskowitz et al., 1993; Himelman et al., 1989). In a recent publication from the Heart of Soweto study, $12 \%$ of newly presenting heart failure cases was attributable to HIV infection (Sliwa et al. 2012). Among asymptomatic HIV infected individuals, studies have documented sub-clinical cardiac involvement to be prevalent (Twagirumukiza et al., 2007), and in other studies cardiac abnormalities in HIV infected patients were only detected at autopsy (Lewis, 1989).

Several factors, apart from the disease progression itself may play part in the progression from asymptomatic cardiac involvement to overt clinical symptoms and heart failure among HIV infected patients. In developing countries where opportunistic infections, low socio-economic status coupled with poor nutrition are a problem, progression towards heart failure may be multifactorial. In a report by Twagirumukiza et al. (2007), a number of factors including smoking, alcohol consumption and low socio economic status were associated with a diagnosis of dilated cardiomyopathy in apparently asymptomatic, HAART naïve HIV infected patients. However it is unclear if these factors are also independently associated with the development of heart failure from any form of cardiac pathology among HIV infected patients. The aim of this study was therefore to determine factors associated with heart failure in a cohort of HIV infected patients already presenting with cardiac complaints at a tertiary health care facility in Dar es Salaam, Tanzania.

\section{Materials and Methods}

\section{Patient population}

This study was designed to prospectively include all known HIV infected patients presenting with cardiac complaints at the medical department, Muhimbili National Hospital, in Dar es Salaam,

\footnotetext{
* Correspondence: Muhammad Bakari; E-mail:drbakari@yahoo.com
} 
Tanzania. The study was conducted between September 2009 and April 2010 and eligible patients were known HIV infected adults ( $\geq 18$ years) presenting with cardiac complaints. Patients were excluded if they were less than 18 years and if they did not consent to participate.

\section{Clinical assessment and laboratory tests}

A structured questionnaire was used to collect information on socio demographic characteristics, other cardiovascular risk factors and history of drugs use, including antiretrovirals. A detailed past and current history of opportunistic infections/illnesses was also recorded. Height and weight measurements were recorded and were used to determine body mass index. Blood pressure was taken using a mercury sphygmomanometer; a set of three readings five minutes apart were taken. The average of the last two readings was taken as the patient's office blood pressure. Hypertension was defined as blood pressure $\geq 140 / 90 \mathrm{mmHg}$ or use of antihypertensive medications.

The New York Heart Association (NYHA) functional classification was used to group patients into classes $1-4$ according to their symptoms at presentation. HIV clinical staging was done using the World Health Organization classification criteria (WHO, 2007). Venous blood was taken and analyzed for a comprehensive chemistry panel, full blood picture and $\mathrm{CD} 4{ }^{+}$T-lymphocyte cell counts ( $\mathrm{CD}_{4}{ }^{+}$cell count). Anaemia was defined as a haemoglobin level $<12 \mathrm{~g} / \mathrm{dl}$ in women and $<13 \mathrm{~g} / \mathrm{dl}$ in men (WHO, 1968). All tests were done at the Muhimbili National Hospital's laboratory, which is the national's reference laboratory.

\section{Echocardiography}

The same licensed cardiologist (PC) performed all echocardiograms. A SONOS 7500 Phillips machine with a 3.5-MHZ transducer was used. Patients were examined in the left lateral decubitus position and the procedure followed the Joint European Association of Echocardiography and American Society of Echocardiography guidelines (Lang et al., 2006). All tests were recorded into Magnetic Optic Disks and measurements were then done offline using the same Phillips Echocardiogram machine. Left ventricular (LV) mass was calculated using an autopsy-validated formula by (Devereux et al., 1986). LV hypertrophy was considered present when LV mass index was $>104 \mathrm{~g} / \mathrm{m}^{2}$ in women and $>116 \mathrm{~g} / \mathrm{m}^{2}$ in men (de Simone et al., 2005). Relative wall thickness was calculated as twice the posterior wall thickness at end diastole divided by LV internal radius at end diastole, and considered increased if $\geq 0.43$ (Roman et al., 1996). LV end diastolic and systolic volumes were measured using Simpson's biplane method and were used to calculate ejection fraction, stroke volume and cardiac output as currently recommended (Lang et al., 2006). LV systolic dysfunction was considered present when ejection fraction was $<50 \%$, and diastolic dysfunction was defined according to the European Study Group on Diastolic Heart Failure criteria (European Study Group on Diastolic Heart, 1998).

Pericardial effusion was considered present when there was an echo free space between the visceral and parietal pericardia that persisted throughout the whole cardiac cycle. Effusion was graded as small when it was less than or equal to $2 \mathrm{~cm}$, and large when it was more than $2 \mathrm{~cm}$ on $2-$ dimensional pictures during diastole. Pulmonary hypertension was defined as echocardiographically estimated pulmonary arterial pressure $\$ 35 \mathrm{mmHg}$ with or without dilated and/or hypertrophied right ventricle and in the presence of dyspnoea. Dilated cardiomyopathy was defined as the presence of all chambers dilatation and global hypokinesia in the absence of features of hypertensive heart disease or any other apparent cause of global dilatation and hypokinesia.

Patients were classified as having hypertensive heart disease if they were hypertensive and found to have LV hypertrophy or concentric remodelling (i.e. increase in relative wall thickness with normal LV mass index), with either systolic or diastolic dysfunction, or both. Heart failure was defined as having NYHA class 3 or 4 with confirmed structural heart abnormality on echocardiography and LV ejection fraction $<50 \%$ or Doppler evidence of LV diastolic dysfunction. A second independent cardiologist $(\mathrm{JL})$ re-read all the $M O$ disks, and a consensus between the two Cardiologists had to be reached before the final diagnosis was concluded. 


\section{Data analysis}

Data was entered and analyzed using the Statistical Package for Social Sciences (SPSS) Version 18. Continuous data are expressed as mean $( \pm S D)$ and categorical data as number (\%). Comparison between groups was done using unpaired Student's t-test for continuous variables and Chi square test for categorical variables. Univariate and finally multivariate binary logistic regression analyses were performed to determine the independent covariates of having a diagnosis of heart failure. A pvalue of less than 0.05 was considered to indicate a statistical significance.

\section{Ethical considerations}

Ethical approval was obtained from the Muhimbili University of Health and Allied Sciences Senate's Research and Publications Committee and all participating patients signed a written consent.

\section{Results}

A total of 102 HIV infected patients presented with cardiac complaints during the 8 months study period. The patients' mean age was 42.4 years (range $=18-72$ years). The proportion of women was $68.6 \%$. Of the 102 patients, 50 (49\%) were in heart failure based on the presence of NYHA class 3 or 4 symptoms and confirmed on echocardiogram. Compared to patients without heart failure, those with heart failure were younger, included more men, and had shorter duration of HIV $(p<0.05)$. They also had lower body mass index, haemoglobin and $\mathrm{CD}_{4}^{+}$cell counts when compared to patients without heart failure, all $\mathrm{p}<0.01$ (Table 1 ).

Table 1: Socio-demographic characteristics and laboratory findings in patients with and without heart failure

\begin{tabular}{|c|c|c|c|}
\hline Characteristic & $\begin{array}{l}\text { Heart failure present } \\
(n=50)\end{array}$ & $\begin{array}{l}\text { No heart failure } \\
(n=52)\end{array}$ & P-value \\
\hline Mean ( \pm SD) Age in years & $39.7 \pm 10.4$ & $45.1 \pm 11.6$ & 0.015 \\
\hline Men, $\mathrm{n}(\%)$ & $21(42.0)$ & $11(21.1)$ & 0.023 \\
\hline Mean ( \pm SD) HIV duration in months & $20 \pm 20$ & $43 \pm 48$ & 0.003 \\
\hline ARV use, $\mathrm{n}(\%)$ & $31(62.0)$ & $39(75.0)$ & 0.157 \\
\hline Mean $( \pm$ SD) duration on ARV in months & $22 \pm 22$ & $37 \pm 28$ & 0.020 \\
\hline Mean ( \pm SD) Height in $\mathrm{cm}$ & $158.6 \pm 7.8$ & $159.5 \pm 7.4$ & 0.549 \\
\hline Mean $( \pm$ SD) Body Weight in kg & $58.2 \pm 10.5$ & $65.5 \pm 14.4$ & 0.005 \\
\hline Mean $( \pm S D)$ BMI in $\mathrm{kg} / \mathrm{m}^{2}$ & $23.1 \pm 3.7$ & $25.8 \pm 5.8$ & 0.007 \\
\hline Mean ( \pm SD) Systolic blood pressure in $\mathrm{mmHg}$ & $126 \pm 23$ & $132 \pm 20$ & 0.134 \\
\hline Mean ( \pm SD) Diastolic blood pressure in $\mathrm{mmHg}$ & $78 \pm 19$ & $83 \pm 11$ & 0.062 \\
\hline Hypertension, n (\%) & $22(44.0)$ & $23(44.2)$ & 0.981 \\
\hline Attained primary or less education level, n (\%) & $42(84)$ & $34(65.4)$ & 0.031 \\
\hline Smoking, n (\%) & $8(16)$ & $1(1.9)$ & 0.012 \\
\hline Alcohol intake, n (\%) & $16(32)$ & $7(13.5)$ & 0.025 \\
\hline Pulse rate (beats/min) & $97 \pm 13$ & $93 \pm 21$ & 0.359 \\
\hline Mean ( \pm SD) haemoglobin $(g / d l)$ & $9.6 \pm 2.7$ & $11.4 \pm 4.0$ & 0.008 \\
\hline Anaemia n (\%) & $43(86.0)$ & $32(61.5)$ & 0.005 \\
\hline Mean $( \pm$ SD) Cholesterol & $4.0 \pm 1.4$ & $5.2 \pm 1.7$ & $<0.001$ \\
\hline Mean ( \pm SD) Creatinine & $274 \pm 420$ & $108 \pm 69$ & 0.006 \\
\hline Mean ( \pm SD) Total WBC count & $5.7 \pm 3.7$ & $5.6 \pm 3.1$ & 0.887 \\
\hline Mean $( \pm \mathrm{SD})$ ESR $\left(\mathrm{mmhr}^{-1}\right)$ & $78 \pm 34$ & $64 \pm 44$ & 0.094 \\
\hline Mean $( \pm \mathrm{SD}) \mathrm{CD}_{4}^{+}$cell count & $209 \pm 192$ & $385 \pm 259$ & $<0.001$ \\
\hline
\end{tabular}

As expected, significantly more patients with heart failure presented with shortness of breath, orthopnoea, paroxysmal nocturnal dyspnoea and oedema of lower limbs when compared to patients without heart failure ( $p<0.05$ ), (Table 2$)$. On the other hand, palpitations and chest pain as presenting symptoms were unspecific, being not significantly different between the two groups of patients (Table 2). 
Table 2: Presenting symptoms in patients with and without heart failure

\begin{tabular}{llll}
\hline Symptom & $\begin{array}{l}\text { Heart failure present (n } \\
\text { (50) }\end{array}$ & $\begin{array}{l}\text { No heart failure } \\
\text { (n=52) }\end{array}$ & P-value \\
\hline Palpitations, $\mathrm{n}(\%)$ & $45(90.0)$ & $48(92.3)$ & 0.681 \\
Shortness of breath, $\mathrm{n}(\%)$ & $44(88.0)$ & $27(51.9)$ & $<0.001$ \\
Orthopnoea, $\mathrm{n}(\%)$ & $25(50.0)$ & $8(15.4)$ & $<0.001$ \\
Paroxysmal nocturnal dyspnoea, $\mathrm{n}(\%)$ & $16(32.0)$ & $4(7.7)$ & 0.002 \\
Cough, $\mathrm{n}(\%)$ & $31(62.0)$ & $16(30.8)$ & 0.002 \\
Chest pain, $\mathrm{n}(\%)$ & $17(34.0)$ & $12(23.1)$ & 0.221 \\
Oedema of lower limbs, $\mathrm{n}(\%)$ & $31(62.0)$ & $11(21.2)$ & $<0.001$ \\
\hline
\end{tabular}

The main causes of heart failure were hypertensive heart disease, pulmonary hypertension and dilated cardiomyopathy. Anaemia as the sole cause of heart failure was present in $8 \%$. Other causes of heart failure were congenital pulmonary stenosis (2\%), and aneurysm of the aortic root, with severe aortic regurgitation (4\%) (Figure 1 ).
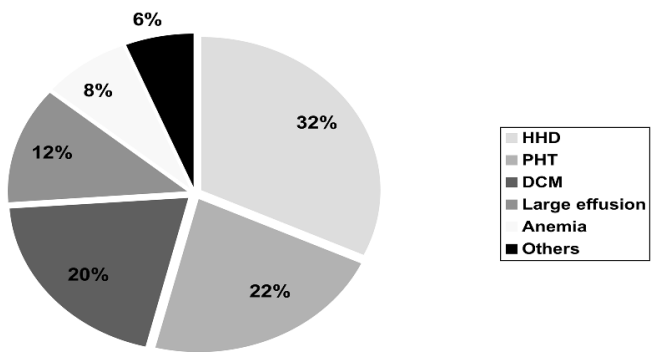

Figure 1: Frequency distribution of causes of heart failure in the $\mathbf{5 0}$ patients with heart failure Key: $\mathrm{HHD}=$ hypertensive heart disease, $\mathrm{PHT}=$ pulmonary hypertension, $\mathrm{DCM}$ = dilated cardiomyopathy

Previous history of tuberculosis (pulmonary and extra-pulmonary) was the only opportunistic illness that was significantly more prevalent among patients with heart failure compared to those without heart failure (50\% versus $17.3 \%$ respectively), $\mathrm{p}<0.001$ (Table 3 ).

Table 3: Opportunistic infections among patients with and without heart failure

\begin{tabular}{llll}
\hline Opportunistic infection & Heart failure present $(\mathbf{n = 5 0})$ & $\begin{array}{l}\text { No heart failure }(\mathbf{n}=\mathbf{P} \text {-value } \\
\mathbf{5 2}\end{array}$ \\
\hline Oral thrush n (\%) & $12(24)$ & $11(21.2)$ & 0.731 \\
History of tuberculosis n (\%) & $25(50)$ & $9(17.3)$ & $<0.001$ \\
Meningitis n (\%) & $2(4)$ & $0(0)$ & 0.145 \\
Pruritic Papular Eruption, $\mathrm{n}(\%)$ & $20(40)$ & $12(23.1)$ & 0.066 \\
Kaposi's sarcoma n (\%) & $2(4)$ & $3(5.8)$ & 0.679 \\
Herpes Zoster n (\%) & $13(26)$ & $17(32.7)$ & 0.458 \\
Recurrent pneumonia n (\%) & $11(22)$ & $11(21.2)$ & 0.917 \\
Recurrent oral ulceration n (\%) & $8(16)$ & $8(15.4)$ & 0.932 \\
Prolonged diarrhoea n (\%) & $7(14)$ & $3(5.8)$ & 0.162 \\
Prolonged fever n (\%) & $17(34)$ & $15(46.9)$ & 0.575 \\
Oesophageal candidiasis n (\%) & $1(2)$ & $0(0)$ & 0.305 \\
Generalized lymphadenopathy n (\%) & $12(24)$ & $6(11.5)$ & 0.099 \\
Seborrhoeic dermatitis n (\%) & $3(6)$ & $0(0)$ & 0.073 \\
Fungal nail infection n (\%) & $10(20)$ & $6(11.5)$ & 0.240 \\
\hline
\end{tabular}


On echocardiography, patients with heart failure had significantly larger ventricles, larger left atrium diameter as well as higher LV mass and LV mass index when compared to patients without heart failure (<0.001), (Table 4).

Table 4: Echocardiographic parameters in patients with and without heart failure

\begin{tabular}{|c|c|c|c|}
\hline Variable & $\begin{array}{l}\text { Heart failure present }(n= \\
50 \text { ) }\end{array}$ & $\begin{array}{l}\text { No heart failure, }(n= \\
52)\end{array}$ & P-value \\
\hline RV end diastolic diameter $(\mathrm{cm})$ & $3.3 \pm 0.7$ & $2.7 \pm 0.4$ & $<0.001$ \\
\hline LV end diastolic diameter $(\mathrm{cm})$ & $5.14 \pm 1.10$ & $4.15 \pm 0.47$ & $<0.001$ \\
\hline Interventricular septum $(\mathrm{cm})$ & $1.09 \pm 0.28$ & $1.14 \pm 0.32$ & 0.484 \\
\hline Posterior wall (cm) & $1.03 \pm 0.25$ & $1.01 \pm 0.23$ & 0.837 \\
\hline LV end systolic diameter $(\mathrm{cm})$ & $3.81 \pm 1.30$ & $2.49 \pm 0.37$ & $<0.001$ \\
\hline LA end systolic diameter $(\mathrm{cm})$ & $4.05 \pm 0.72$ & $3.33 \pm 0.58$ & $<0.001$ \\
\hline Relative wall thickness & $0.42 \pm 0.15$ & $0.49 \pm 0.14$ & 0.017 \\
\hline LV mass (g) & $211 \pm 84$ & $153 \pm 56$ & $<0.001$ \\
\hline LV mass index $\left(\mathrm{g} / \mathrm{m}^{2}\right)$ & $135 \pm 56$ & $91 \pm 27$ & $<0.001$ \\
\hline Fractional shortening (\%) & $28 \pm 12$ & $39 \pm 5$ & $<0.001$ \\
\hline Ejection fraction (\%) & $48 \pm 16$ & $65 \pm 6$ & $<0.001$ \\
\hline Cardiac index $\left(1 / \mathrm{min} / \mathrm{m}^{2}\right)$ & $3.8 \pm 1.4$ & $4.0 \pm 1.5$ & 0.650 \\
\hline Stroke volume index $\left(\mathrm{ml} / \mathrm{m}^{2}\right)$ & $42 \pm 17$ & $42 \pm 13$ & 0.873 \\
\hline E/A ratio & $1.3 \pm 0.6$ & $0.9 \pm 0.4$ & 0.003 \\
\hline Isovolumic relaxation time (msec) & $65 \pm 24$ & $76 \pm 21$ & 0.033 \\
\hline E deceleration time (msec) & $161 \pm 64$ & $187 \pm 57$ & 0.063 \\
\hline
\end{tabular}

$\mathrm{RV}=$ right ventricular, $\mathrm{LV}=$ left ventricular, $\mathrm{LA}=$ left atrium

As expected, LV systolic function as assessed by endocardial fractional shortening and ejection fraction was significantly lower in patients with heart failure, all $p<0.001$, (Table 4). The peak early to atrial transmitral Doppler flow velocity (E/A) ratio was higher in patients with heart failure and both the isovolumic relaxation time and $\mathrm{E}$ deceleration time were shorter in patients with heart failure, reflecting restrictive physiology, (Table 4).

In multivariate logistic regression analysis, male gender, having attained less than secondary school education, previous history of tuberculosis and lower haemoglobin level were independently associated with the diagnosis of heart failure $(p<0.05)$ (Table 5$)$. These associations were independent of age and $\mathrm{CD}_{4}^{+}$cell count.

Table 5: Independent covariates of having a diagnosis of heart failure identified by logistic regression analysis

\begin{tabular}{lll}
\hline Variable & Odds Ratio (95\%Confidence Interval) & P-value \\
\hline Age (years) & $0.96(0.92-1.00)$ & 0.078 \\
Male gender & $4.03(1.24-13.08)$ & 0.020 \\
Primary education or less & $4.91(1.46-16.51)$ & 0.010 \\
Previous history of tuberculosis & $3.01(1.32-11.56)$ & 0.014 \\
Haemoglobin level $(\mathrm{g} / \mathrm{dl})$ & $0.83(0.71-0.97)$ & 0.021 \\
CD4 cell count $($ cells $/ \mu \mathrm{l})$ & $0.99(0.99-1.00)$ & 0.371 \\
\hline
\end{tabular}

\section{Discussion}

From echocardiographic studies in developed and developing world, it is known that cardiac involvement in HIV infected patients is common (Himelman et al., 1989; Lewis, 1989; Herskowitz et al., 1993; Longo-Mbenza et al., 1998; Nzuobontane et al., 2002; Twagirumukiza et al., 2007; Butt et al., 2011) and that although small in contribution, cardiac abnormalities are a known cause of mortality among HIV infected patients (Longo-Mbenza et al., 1998; Bonnet et al., 2002; Smith et al., 2010; Leone et al., 2011). In Africa, experts of the subject have previously suggested that echocardiogram should be performed in HIV infected patients presenting with cardiac symptoms or signs (Magula et al., 2003). However, few studies have reported on echocardiographic findings in HIV infected patients 
presenting with cardiac symptoms, and there is paucity of data from studies addressing factors associated with heart failure in such patients.

The present study has added to the current knowledge on cardiac involvement in HIV infected patients in Africa by demonstrating that heart failure is present in almost half of HIV infected patients presenting with cardiac symptoms, that hypertensive heart disease is the main cause of heart failure in such patients, and that anaemia and previous history of tuberculosis infection are modifiable factors that are independently associated with heart failure in HIV infected patients.

Our finding that heart failure is present in $49 \%$ of HIV infected patients with cardiac symptoms is higher than that reported in the Heart of Soweto study, in which $29 \%$ of HIV infected patients who presented de novo with cardiac complaints had LV systolic dysfunction (Sliwa et al., 2012). The difference could be due to the fact that in their study, HIV testing was done on suspicion, and as noted in our results some of the causes of heart failure, particularly hypertensive heart disease may not directly be related to HIV. Hence such cases could have been missed out.

Conflicting results have been reported on the association between hypertension and HIV infection, with some suggesting that hypertension is more common in HIV infected patients (Gazzaruso et al., 2003; Seaberg et al.,2005) while others have found no association (Bergersen et al., 2003). In our study, hypertensive heart disease was the main cause of heart failure and it probably reflects the fact that hypertension is highly prevalent among adults in urban Dar es Salaam (Njelekela et al., 2001). Furthermore, hypertensive heart disease has been reported as being the main cause of heart failure in several African populations (Stewart et al., 2008; Ojji et al., 2009). Of note, we have previously reported that neither the duration of HIV nor the use of antiretroviral medications was independently associated with hypertensive heart disease in HIV infected patients with cardiac symptoms. (Chillo et al., 2012). On the other hand, our findings that pulmonary hypertension, dilated cardiomyopathy and large pericardial effusion were also important causes of heart failure is in keeping with findings from previous reports that the three are important cardiac pathologies in HIV infected patients in Africa (Cegielski et al., 1990; Longo-Mbenza et al., 1998; Nzuobontane et al., 2002; Magula et al., 2003; Twagirumukiza et al., 2007).

We found anaemia to be very common (73.5\%) in the current study, and being significantly higher in those with heart failure (86\% vs $61.5 \%$ ). Furthermore, lower haemoglobin was found to be independently associated with heart failure in multivariate analysis. As is known, the relationship between anaemia and heart failure is double sided. While on one hand anaemia exacerbates heart failure, on the other hand heart failure can cause anaemia. We believe that, at least in this study, anaemia has exacerbated heart failure, as the prevalence of anaemia has previously been reported to be high in HIV infected and antiretroviral naïve patients in Tanzania (Nagu et al., 2012). In fact, severe anaemia was the only responsible cause of heart failure in four patients in this study.

Our finding that previous history of tuberculosis was independently associated with heart failure was somehow unexpected and information linking the two is lacking although tuberculosis is known to further impair immunity in HIV infected patients (Whalen et al., 1995). This could have contributed to the occurrence of specific forms of HIV associated cardiomyopathy like dilated cardiomyopathy, which is known to occur in patients with advanced immunodepression (Jacob et al., 1992; Nzuobutane et al., 2002; Twagirumuikiza et al., 2007; Chillo et al., 2012). Of note is the fact that in our study low $\mathrm{CD}_{4}{ }^{+}$count was associated with heart failure in univariate analysis.

We found an interesting gender difference in relation to heart failure in this study. Firstly, men were less represented (only $31 \%$ in the total population) probably reflecting the gender difference in the prevalence of HIV in the general population (THMIS, 2008). This observation has been reported in previous studies among HIV infected patients in Tanzania, with men comprising of only a third of the HIV infected subjects (Nagu et al., 2008; Mugusi et al., 2010). Secondly, in this study male gender was independently associated with the diagnosis of heart failure in multivariate analysis, a finding that has previously been reported in both population and hospital based studies. These studies have reported that the prevalence of heart failure is higher among men, and men often have a higher probability of dying from heart failure when compared to women (McKee et al., 
1971; Adams et al., 1996, 1999). This could be one of the explanations, but it is also possible that other factors like cigarette smoking and alcohol consumption may have confounded this association as more men in this study were smokers ( $28.1 \%$ vs $0 \%$ ) and took alcohol ( $50 \%$ vs $10 \%)$ when compared to women. Furthermore, alcohol consumption and cigarette smoking were associated with heart failure in univariate analysis in our study, similar to the findings by Twagirumukiza et al. (2007).

In sub-Saharan Africa, low education level is often linked to low socio-economic status, therefore our finding that low education was independently associated with the diagnosis of heart failure among HIV infected patients is in keeping with reports from other studies in sub-Saharan Africa that low socio-economic status is an independent predictor of cardiac disease in HIV infected patients (Longo-Mbenza et al., 1998; Twagirumukiza et al., 2007). Patients with low socio economic status often have less access to health care and often lack better understanding of their health, which could explain the increased likelihood of these patients to present late to hospital when the disease is more advanced.

The limitation of this study is probably the fact that we did not use the Framingham criteria to actively look for congestive heart failure and therefore some patients without overt symptoms may have been missed. However we believe that we captured all those with symptomatic heart failure since we used both symptoms and echocardiography to diagnose heart failure.

In conclusion, we have shown that heart failure is a common finding among HIV infected patients with cardiac complaints and is associated with modifiable and non modifiable factors. These findings emphasize the importance of early diagnosing and treating tuberculosis, correcting anaemia and control of hypertension among HIV infected patients.

\section{Conflict of interest}

The authors declare no conflict of interest

\section{References}

Adams Jr, K.F., Sueta, C.A., Gheorghiade, M., O'Connor, C.M., Schwartz, T.A., Koch, G.G., Uretsky, B., Swedberg, K., McKenna, W., Soler-Soler, J. \& Califf, R.M. (1999). Gender differences in survival in advanced heart failure. Insights from the FIRST study. Circulation 99, 1816-1821.

Adams Jr, K.F., Dunlap, S.H., Sueta, C.A., Clarke, S.W., Patterson, J.H., Blauwet, M.B., Jensen, L.R., Tomasko, L. \& Koch G. (1996). Relation between gender, etiology and survival in patients with symptomatic heart failure. J ournal of American College of Cardiologist 28, 1781-1788.

Bergersen, B.M., Sandvik, L., Dunlop, O., Birkeland, K. \& Bruun, J.N. (2003). Prevalence of hypertension in HIV-positive patients on highly active retroviral therapy (HAART) compared with HAART-naive and HIV-negative controls: results from a Norwegian study of 721 patients. Eur J Clin Microbiol Infect Dis 22, 731-736.

Bonnet, F., Morlat, P., Chêne, G., Mercié, P., Neau, D., Chossat, I., Decoin, M., Djossou, F., Beylot, J., \& Dabis, F. (2002) Causes of death among HIV-infected patients in the era of highly active antiretroviral therapy, Bordeaux, France, 1998-1999. HIV Medicine 3, 195-199.

Butt, A.A., Chang, C.C., Kuller, L., Goetz, M.B., Leaf, D., Rimland, D., Gibert, C.L., Oursler, K.K., Rodriguez-Barradas, M.C., Lim, J., Kazis, L.E., Gottlieb, S., Justice, A.C. \& Freiberg, M.S. (2011). Risk of heart failure with human immunodeficiency virus in the absence of prior diagnosis of coronary heart disease. Archives of Internal Medicine 171, 737-743.

Cegielski, J.P., Ramaiya, K., Lallinger, G.J., Mtulia, I.A. \& Mbaga, I.M. (1990) Pericardial disease and human immunodeficiency virus in Dar es Salaam, Tanzania. Lancet 335, 209-212.

Chillo, P., Bakari, M. \& Lwakatare, J. (2012) Echocardiographic diagnoses in HIV-infected patients presenting with cardiac symptoms at Muhimbili National Hospital in Dar es Salaam, Tanzania. Cardiovascular J ournal of Africa 23, 90-97. 
de Simone, G., Devereux, R.B., Maggioni, A.P., Gorini, M., de Divitiis, O. \& Verdecchia, P. (2005). Different normalizations for body size and population attributable risk of left ventricular hypertrophy: the MAVI study. American J ournal of Hypertension 18, 288-293.

Roman, M.J., Pickering, T.G., Schwartz, J.E., Pini, R. \& Devereux, R.B. (1996). Relation of arterial structure and function to left ventricular geometric patterns in hypertensive adults. Journal of American College of Cardiologists 28, 751-756.

Devereux, R.B., Alonso, D.R., Lutas, E.M., Gottlieb, G.J., Campo, E., Sachs, I. \& Reichek, N. (1986) Echocardiographic assessment of left ventricular hypertrophy: comparison to necropsy findings. American J ournal of Cardiology 57, 450-458.

European Study Group on Diastolic Heart (1998). How to diagnose diastolic heart failure. European Heart J ournal 19, 990-1003.

Gazzaruso, C., Bruno, R., Garzaniti, A., Giordanetti, S., Fratino, P., Sacchi, P. \& Filice, G. (2003). Hypertension among HIV patients: prevalence and relationships to insulin resistance and metabolic syndrome. J ournal of Hypertension 21, 1377-1382.

Herskowitz, A., Vlahov, D., Willoughby, S., Chaisson, R.E., Schulman, S.P., Neumann, D.A. \& Baughman, K.L. (1993) Prevalence and incidence of left ventricular dysfunction in patients with human immunodeficiency virus infection. American J ournal of Cardiology 71, 955-958.

Himelman, R.B., Chung, W.S., Chernoff, D.N., Schiller, N.B. \& Hollander, H. (1989). Cardiac manifestations of human immunodeficiency virus infection: a two-dimensional echocardiographic study. J ournal of American College of Cardiologists 13,1030-1036.

Jacob, A.J., Sutherland, G.R., Bird, A.G., Brettle, R.P., Ludlam, C.A., McMillan, A., \& Boon, N.A. (1992) Myocardial dysfunction in patients infected with HIV: prevalence and risk factors. British Heart J ournal 68, 549-553.

Lang, R.M., Bierig, M., Devereux, R.B., Flachskampf, F.A., Foster, E., Pellikka, P.A., Picard, M.H., Roman, M.J., Seward, J., Shanewise, J., Solomon, S., Spencer, K.T., St John Sutton, M., Stewart, W. (2006) Recommendations for chamber quantification. European Journal of Echocardiography 7, 79-108.

Leone, S., Gregis, G., Quinzan, G., Velenti, D., Cologni, G., Soavi, L., Ravasio, V., Ripamonti D., Suter, F. \& Maggiolo, F. (2011). Causes of death and risk factors among HIV-infected persons in the HAART era: analysis of a large urban cohort. Infection 39, 13-20.

Lewis W (1989). AIDS: cardiac findings from 115 autopsies. Progress in Cardiovascular Diseases 32, 207215.

Longo-Mbenza, B., Seghers, K.V., Phuati, M., Bikangi, F.N. \& Mubagwa, K. (1998). Heart involvement and HIV infection in African patients: determinants of survival. International Journal of Cardiology 64, 63-73.

Magula, N.P. \& Mayosi, B.M. (2003). Cardiac involvement in HIV-infected people living in Africa: a review. Cardiovascular J ournal of South Africa 14, 231-237.

McKee, P.A., Castelli, W.P., McNamara, P.M., \& Kannel, W.B. (1971) The natural history of congestive heart failure: the Framingham study. New England J ournal of Medicine 285, 1441-1446.

Mugusi, S.F., Mwita, J.C., Francis, J.M., Aboud, S., Bakari, M., Aris, E.A., Swai, A.B., Mugusi, F.M., Pallangyo, K. \& Sandstrom, E. (2010) Effect of improved access to antiretroviral therapy on clinical characteristics of patients enrolled in the HIV care and treatment clinic, at Muhimbili National Hospital (MNH), Dar es Salaam, Tanzania. BMC Public Health 10, 291.

Nagu, T.J., Kanyangarara, M., Hawkins, C., Hertmark, E., Chalamila, G., Spiegelman, D., Mugusi, F. \& Fawzi, W. (2012) Elevated alanine aminotransferase in antiretroviral-naive HIV-infected African patients: magnitude and risk factors. HIV Medicine 13, 541-548.

Nagu, T.J., Bakari, M. \& Matee, M. (2008). Hepatitis A, B and C viral co-infections among HIV-infected adults presenting for care and treatment at Muhimbili National Hospital in Dar es Salaam, Tanzania. BMC Public Health 8, 416.

Njelekela, M., Negishi, H., Nara, Y., Tomohiro, M., Kuga, S., Noguchi, T., Kanda, T., Yamori, M., Mashalla, Y., Jian Liu, L., Mtabaji, J., Ikeda, K. \& Yamori Y. (2001) Cardiovascular risk factors in Tanzania: a revisit. Acta Tropica 79, 231-239. 
WHO (1968) Nutritional anaemias. Report of a WHO scientific group. World Health Organization Technical Report Series 405, 5-37.

Nzuobontane, D., Blackett, K.N. \& Kuaban, C. (2002) Cardiac involvement in HIV infected people in Yaounde, Cameroon. Postgrad Med J 78, 678-681.

Ojji, D.B., Alfa, J., Ajayi, S.O., Mamven, M.H. \& Falase, A.O. (2009) Pattern of heart failure in Abuja, Nigeria: an echocardiographic study. Cardiovascular J ournal of Africa 20, 349-852.

Seaberg, E.C., Muñoz, A., Lu, M., Detels, R., Margolick, J.B., Riddler, S.A., Williams, C.M. \& Phair, J.P. (2005) Association between highly active antiretroviral therapy and hypertension in a large cohort of men followed from 1984 to 2003. AIDS 19, 953-960.

Sliwa, K., Carrington, M.J., Becker, A., Thienemann, F., Ntsekhe, M. \& Stewart, S. (2012) Contribution of the human immunodeficiency virus/acquired immunodeficiency syndrome epidemic to de novo presentations of heart disease in the Heart of Soweto Study cohort. European Heart J ournal 33, 866-874.

Smith, C., Sabin, C.A., Lundgren, J.D., Thiebaut, R., Weber, R., Law, M., Monforte, A., Kirk, O., FriisMoller, N., Phillips, A., Reiss, P., El Sadr, W., Pradier, C. \& Worm, S.W. (2010) Factors associated with specific causes of death amongst HIV-positive individuals in the D:A:D Study. AIDS 24, 1537-1548.

Stewart, S., Wilkinson, D., Hansen, C., Vaghela, V., Mvungi, R., McMurray, J. \& Sliwa, K.(2008). Predominance of heart failure in the Heart of Soweto Study cohort: emerging challenges for urban African communities. Circulation 118, 2360-2367.

THMIS (2008) Tanzania HIV/AIDS and Malaria Indicator Survey 2007-08. Dar es Salaam.

Twagirumukiza, M., Nkeramihigo, E., Seminega, B., Gasakure, E., Boccara, F. \& Barbaro, G. (2007) Prevalence of dilated cardiomyopathy in HIV-infected African patients not receiving HAART: a multicenter, observational, prospective, cohort study in Rwanda. Current HIV Research 5, 129137.

Whalen, C., Horsburgh, C.R., Hom, D., Lahart, C., Simberkoff, M. \& Ellner, J. (1995) Accelerated course of human immunodeficiency virus infection after tuberculosis. American Journal of Respiratory and Critical Care Medicine 151, 129-135.

WHO (2007) WHO case definitions of HIV for surveillance and revised clinical staging and immunological classification of HIV-related disease in adults and children. World Health Organization, Geneva. 